Sustinere

Journal of Environment and Sustainability

Volume 4 Issue 1 (2020) 24-32

Print ISSN: 2549-1245 Online ISSN: 2549-1253

Website: https://sustinerejes.com E-mail: sustinere.jes@iain-surakarta.ac.id

\title{
RESEARCH PAPER \\ Focal validation mechanism for Lombok earthquake with image analysis of satellite radar and crust movement GPS observation
}

\author{
I Putu Pudja* \\ Sekolah Tinggi Meteorologi Klimatologi dan Geofisika South Tangerang, Indonesia \\ Article history: \\ Received 9 January 2020 | Accepted 24 April 2020 | Available online 30 April 2020
}

\begin{abstract}
Lombok Earthquake on August 5 and August 19, 2018, traces of deformation were analyzed with satellite image data to determine vertical deformation in the form of uplift on the ground surface. Earthquake wave analysis provides data on the mechanism at the epicenter in the form of a fault, the major forces axis in the form of the P axis, as well as the T axis, in addition to location and strength. The results of the focal analysis showed that the Lombok earthquake was an earthquake on the rising fault, the results of satellite radar image analysis showed the corresponding results, where the maximum increase occurred on the lip of the fault block in the form of a hanging wall. The direction of the acting force is indicated by the Axis $\mathrm{P}$, in accordance with the research results of the Lombok earth crust movement, namely the N-NE Direction.
\end{abstract}

Keywords: Lombok earthquake; vertical deformation; focal mechanism

\section{Introduction}

Lombok earthquake occurred from July to August 2018 with its peak strength on 29 July 2018, 5 August 2018, and 19 August 2018 resulted in 336 fatalities. 1.353 people were injured and thousands of building damage, with economic losses reaching Rp. 5.04 Trillion (Nugroho et al., 2009). Victims and damage seemed to spread throughout the region, with most victims in North Lombok Regency. There were a number of casualties and damages due to the earthquakes that occurred sequentially in a relatively short interval of time and were followed by many aftershocks. Figure 1 shows the frequency of the aftershocks.

The surface conditions of Lombok Island covered by tuff are very susceptible to deformation due to tectonic forces whose energy is released during home. This style occurs because of the position of the island of Lombok, which is flanked by two earthquake regions stretching from west to east. In the South, it stretches Sunda Mega Thrust and in the North, it stretches Flores Back Thrust. Sunda Mega Thrust is an Indo-Australian plate tectonic meeting (oceanic plate) with Eurasia (continental plate). The Indo-Australian oceanic plate in the South

${ }^{*}$ Corresponding author. E-mail: ipt_pudja@yahoo.com https://doi.org/10.22515/sustinere.jes.v4i1.92 
infiltrates under the Eurasian slab continental plate in the North, both of which are relatively pressing against each other. Due to the relative pressure from the South from these two plates and the impact of the movement to the west, the Pacific plate tectonics in the Northeast forms the Back Thrust of Flores. Lombok Island and other islands in Nusa Tenggara is the area squeezed by two active earthquake areas, as shown in Figure 2.

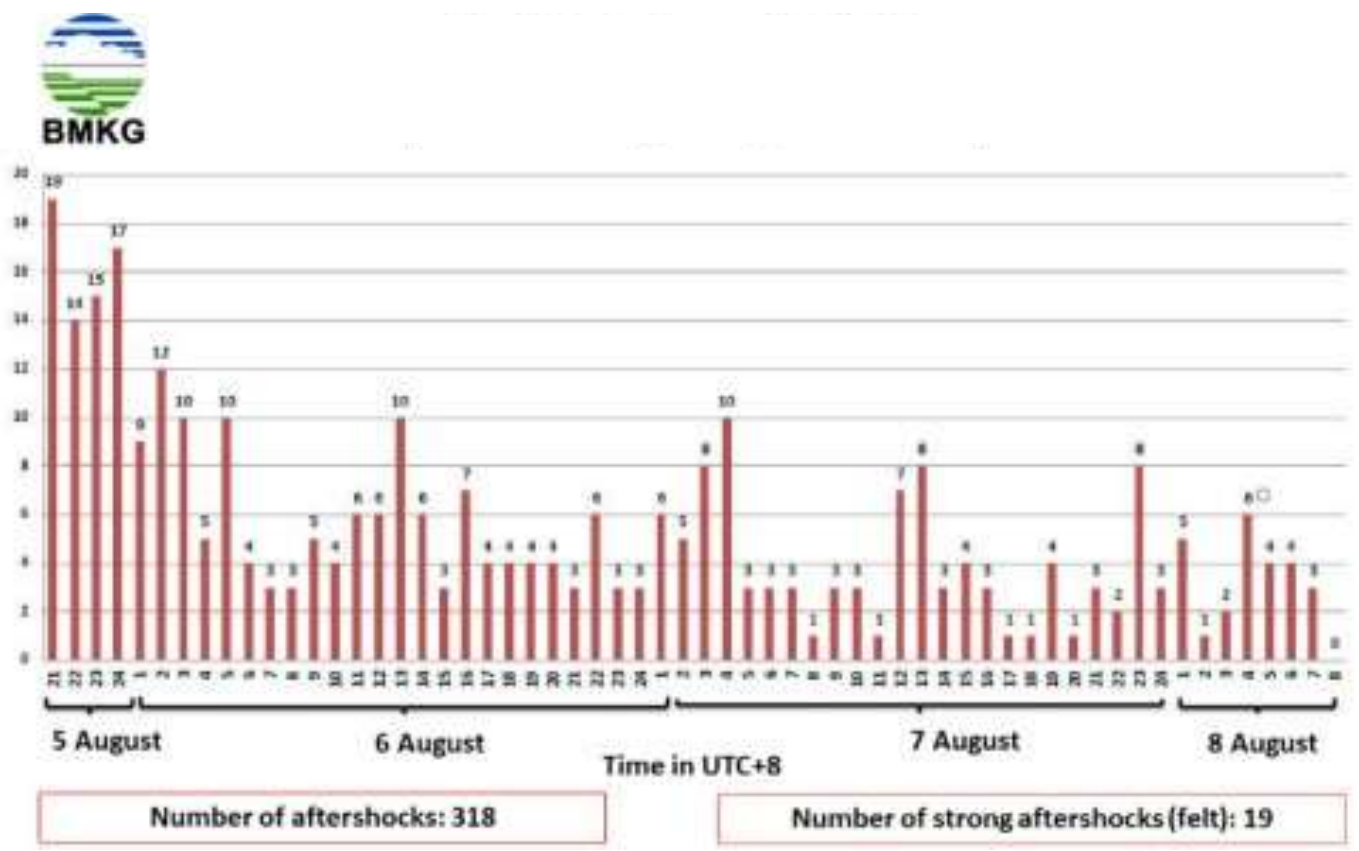

Figure 1. Hourly aftershocks recorded following the M 7.0 Lombok Lombok earthquake

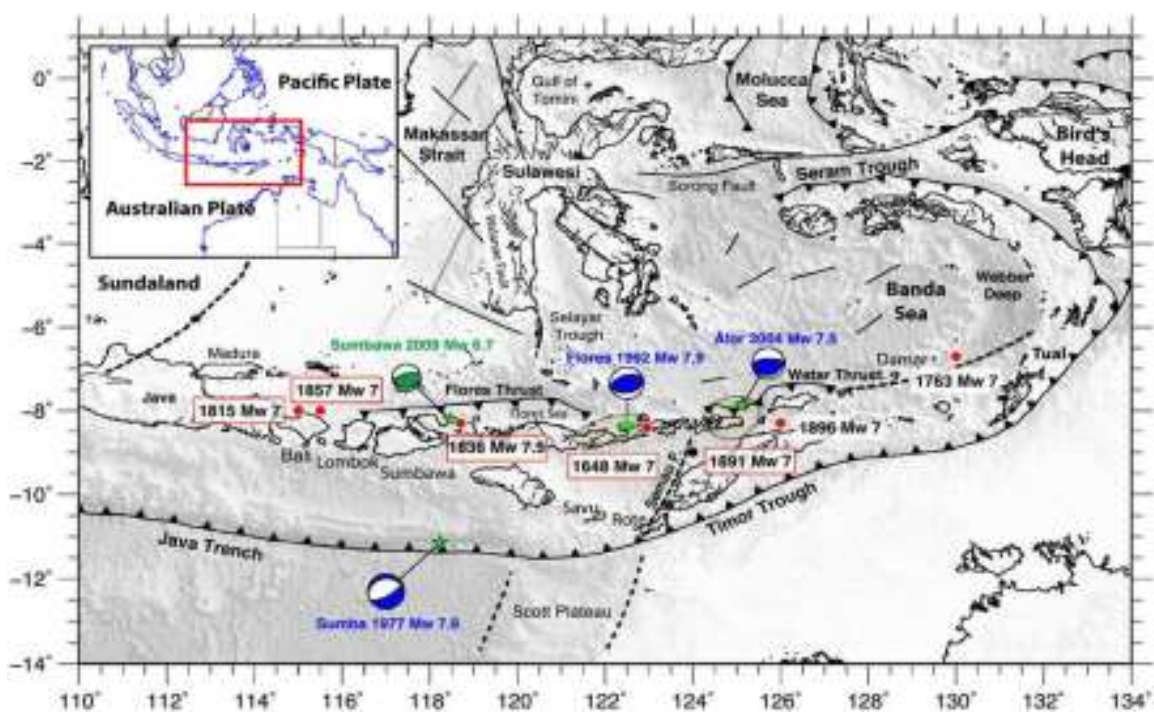

Figure 2. Tectonic maps around Lombok (The concensational, 2018)

This earthquake is not as usual, in which one that normally shakes and damages Lombok is centered in groups in the Flores Sea, Northeast of Lombok, or in the active seafloor areas in the 
Northwest of Lombok (Ghose \& Oike, 1988). Seismicity around Lombok is seen far away in the Southern waters in the Mega Thrust segment and its surroundings and also in the North of the Flores Back Thrust. Therefore, from the epicenter, it looks shifted from the active area of the previous earthquake.

This earthquake is very interesting because the area of damage is very broad which indicates deformation has occurred in the earth's crust due to tectonic forces causing the earthquake. Deformation that occurs can be analyzed including 1) earthquake signal (seismogram) in the form of a focal solution mechanism, 2) continuous observation on the surface of the earth with GPS (Geo Positioning System), and 3) analysis of satellite images that periodically circle and capture of earth surface images. In this study, the results of seismogram analysis are focal mechanisms compared with GPS observations and satellite analysis results.

\section{Literature review}

In general, the force system that causes stress and deformation is the compressive force in the form of forces that push against each other with inline work line and the direction of the approaching opposite forces; pulling forces in the form of pulling forces, with the direction of inline forces that moves away, and shear forces in the form of a pair of opposing forces, in parallel working on two sides of material blocks that are side by side. On a global scale (earth), the three force systems work on the tectonic plates forming the earth's crust.

These tectonic plates float on the part of the earth's liquid that is known as magma, which actively moves to create convection currents in the bowels of the earth. This convection current creates the tectonic plates moving relative to one another. It forms a compressive force system in a convergent region where the plates close to one another and forms a pulling force in a divergent area where the tectonic plates are relatively far from one another, as well as the shear force on the side plates that move in relatively opposite directions.

These three systems are the force systems that cause the deformation until the earthquake as a manifestation of the energy released when the level of material ability has passed the breaking point (rupture point).

The movement of this tectonic plate is observed by GPS carried out by the Geospatial Information Agency. From observations with GPS, Lombok Island moves relatively Northward slightly to the East, with variations from one point to another between $6.65-24.95 \mathrm{~mm}$ / year as a result of the pressure from relative movement of the Oceanic plate (Nugroho et al., 2009; Sulaeman \& Minarno, 2019).

Flores Back Thrust as an area of energy accumulation releases its energy as the Lombok earthquake in 2018. In accordance with the name of the stress-energy accumulation area, the deformation will be clearly visible around the fault plane, fault blocks meeting plane where the earthquake occurs.

Observing from the focal mechanism parameters of the earthquake, the horizontal direction of the earth's crust movement will correspond to the direction of the pressure axis (Cronin, 2010). The pressure is a broad unity force, so the azimuth pressure axis and the earth's crust movement from GPS will correspond. According to the elastic rebound theory of Reid (Bolt, 2006), after the earthquake, the deformation will take a long time to return to the condition 
before the earthquake, and it even leaves permanent deformation. The deformation can be in the form of vertical or/and horizontal earth crust shifts, damage to the surface, liquefaction, and others. Vertical deformations on a wide scale include Aceh and Sumatera earthquake on December 26, 2004, and the Tohoku earthquake, Japan on March 11, 2011 (Marshall, 2005). Lifting and liquefaction deformations are closely related to the level of building damage caused by the earthquake (Iwashita et al., 2003; Sasaki \& Tamura, 2004).

Deformation in the form of ground-level removal can be observed by analyzing InSAR satellite radar image data, such as negative removal in the form of land subsidence from year to year. InSAR satellite radar data for land subsidence for the DKI Jakarta area calculated using the DinSAR method shows results that are consistent with the field data using other measurement methods (Cyntia \& Pudja, 2018).

Changes in vertical deformation data as a change before and after the earthquake are compared with the research results on the earth's crust movement with GPS as a continuous motion of the continental plate, as well as the analysis of the results of the earthquake in the form of the focal mechanism as a data during the earthquake. As a hypothesis, the tectonic force direction of the focal mechanism analysis is consistent with the results of satellite radar images and GPS observations.

\section{Research methods}

\section{1. Earthquake}

Data was taken from the United States Geological Survey Office, USGS (USGS, 2018). The earthquakes used in this study were Lombok earthquakes on August 5 and August 19, 2018, with the consideration of both the earthquakes had a strength of M6,9. The 29 July 2018 earthquake could not be used because of the difficulty in analyzing satellite radar data related to this earthquake. The earthquake data is as in Table 1 with the focal mechanism as in Figure 3.

Table 1. Data of Lombok earthquake on 5 and August 19, 2018

\begin{tabular}{ccccccccc}
\hline No. & Day & $\begin{array}{c}\text { Time } \\
\text { UTC }\end{array}$ & M & $\begin{array}{c}\text { East } \\
\text { Longitude }\end{array}$ & $\begin{array}{c}\text { South } \\
\text { Latitude }\end{array}$ & $\begin{array}{c}\mathbf{H} \\
\mathbf{( k m )}\end{array}$ & $\begin{array}{c}\text { Fault } \\
\text { type }\end{array}$ & $\begin{array}{c}\text { Az Axis } \\
\mathbf{P 0 5 / 0 8 / 2 0 1 8} \\
\mathbf{1 9 : 0 8 : 3 8 1 1 6 . 4 4}\end{array}$ \\
\hline 1 & & & 6.9 & $(0)$ & 08,26 & 30.5 & Rise & 4 \\
2 & $19 / 08 / 2018$ & $22: 56: 28$ & 6.9 & 116.63 & 08.32 & 25 & Rise & 4 \\
\hline
\end{tabular}

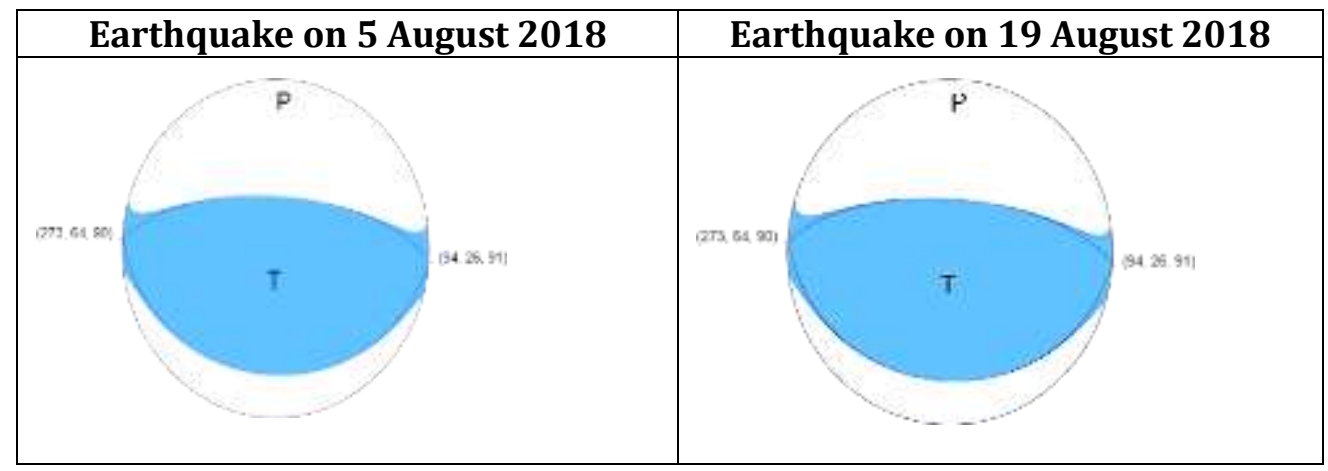

Figure 3. Lombok earthquake focal mechanism (USGS, 2018) 
From the data result of the focal mechanism analysis, both earthquakes show that the fault movement at the time of the earthquake was a rising fault (Thrust Fault), with an azimuth of the earthquake's pressure axis in the direction of 4 degrees.

\section{2. Data of Satellite Radar}

Data of InSAR satellite radar used is Senitel 1A and 1B Satellites. These satellites orbit and circle the earth periodically taking data every 12 days. Data were analyzed by the DinSAR method. Francis et al. (1996) state that the DInSAR technique basically uses two SAR images to identify spatial changes in an area that utilizes coherence in the measurement of interferometric phase from the same surface. The data for this analysis was taken from before and after the earthquake when the satellite took the image of Lombok. The data collection of days is used as in Table 2.

Table 2. Pair of satellite images

\begin{tabular}{lcccc}
\hline $\begin{array}{c}\text { Earthquake } \\
\text { Day }\end{array}$ & $\begin{array}{c}\text { Pair of Image } \\
\text { and Time }\end{array}$ & $\begin{array}{c}\text { Satellite } \\
\text { Name }\end{array}$ & $\begin{array}{c}\text { Perpendicular } \\
\text { Baseline (m) }\end{array}$ & $\begin{array}{c}\text { Time Baseline } \\
\text { (days) }\end{array}$ \\
\hline $\begin{array}{l}\text { Preliminary } \\
\text { Data }\end{array}$ & $\begin{array}{c}30 / 07 / 2018 \\
11 / 08 / 2018\end{array}$ & Sentinel-1A & 23.25 & 12 \\
$09 / 08 / 2018$ & $\begin{array}{l}\text { Sentinel-1A } \\
\text { 14/08/2018 }\end{array}$ & $\begin{array}{l}\text { Sentinel-1B } \\
\text { Sentinel-1B }\end{array}$ & \multirow{2}{*}{20.09} & 6 \\
$19 / 08 / 2018$ & $14 / 08 / 2018$ & $\begin{array}{l}\text { Sentinel-1A } \\
\text { Sentinel }\end{array}$ & & 6 \\
& $20 / 08 / 2018$ & & & \\
\hline
\end{tabular}

The process in processing data of satellite radar is as follows. Data were analyzed with SNAP software on the Windows operating system. The data was processed in pairs, in order to obtain the DEM utility in the Lombok area. Data used for DEM was from the Shuttle Radar Topography Mission (SRTM). The steps in the next process included image coregistration, interferogram, and coherence, deburst, topography, transfer phase, Goldstein filtering, then repeated reviews. With SNAPHU, the coverage phase was carried out. And then the conversion phase was carried out to deformation and geocoding. The last step was making a deformation model map using pairs of data analysis results of before and after the earthquake. The results obtained are described in Figure 4.

From the results of satellite data analysis, it can be seen that the deformation axis is viewed from the North, with deformation in the form of maximum lift in the North and minimum lift in the South. When viewed from the North-South direction with the axis boundary, the East region is more deformed than the West, especially the North Bank of Lombok.

\section{3. GPS Data}

A comparative data analysis results of movements that occur due to the tectonic force system was done by (Sulaeman et al., 2019) and (H. Nugroho et al., 2009). Although both of them did the research at different time periods, both showed the direction of movement dominantly occurred toward the North with slightly to the East. Therefore in general, it can be said that the 
direction of the shift that occurred at the surface of Lombok was toward the North, slightly to the East (N-NE).

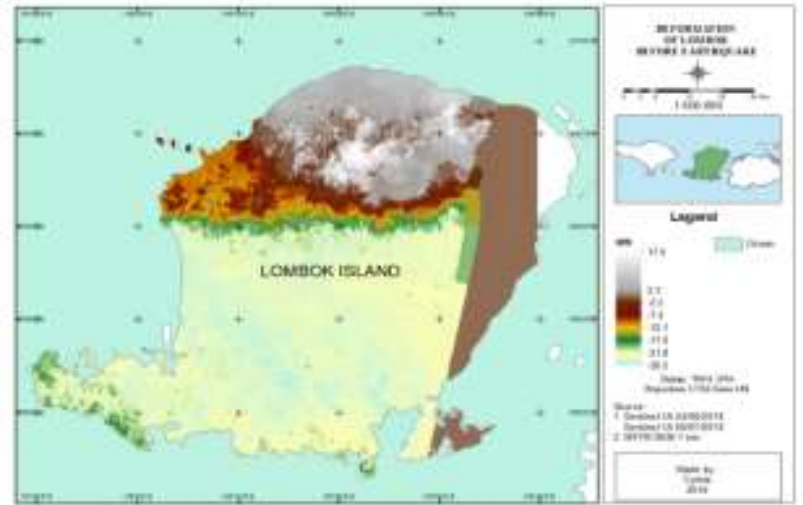

(a)

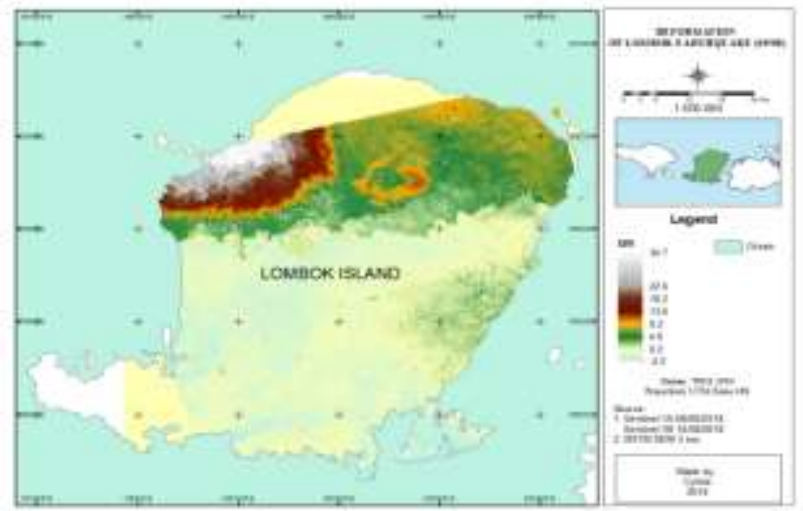

(c)

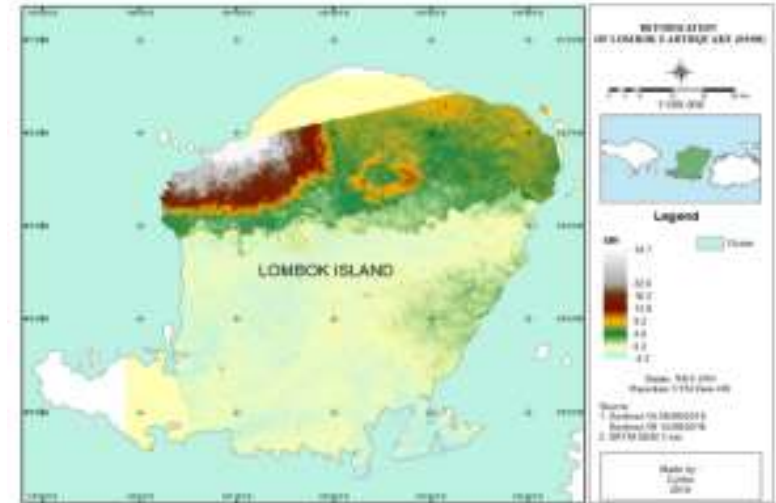

(b)

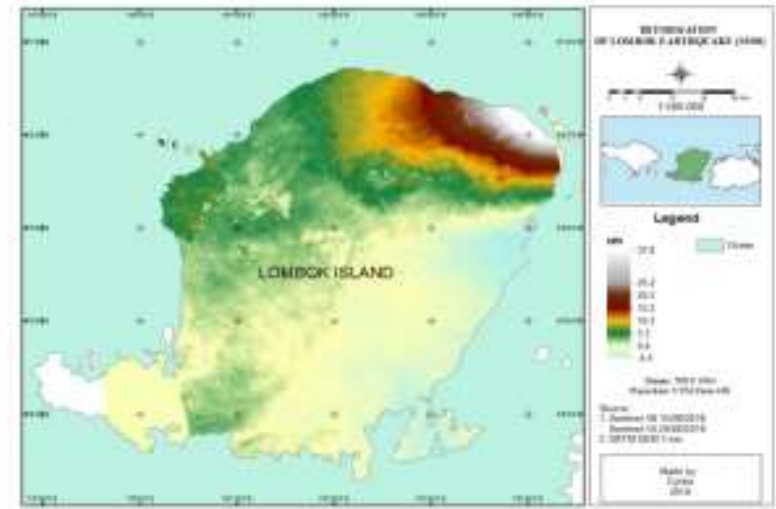

(d)

Figure 4. Deformation of Lombok island before and after the earthquake. (a) Results of data analysis: 24/06 and 06 / 07-2018, (b) Results of data analysis: 07/30 and 11/08-2018, (c) Results of data analysis: 08/08 and 14/08/08-2018, (d) Results of data analysis: 14/08 and 20/08 -2018

\section{Results}

From the results of the research during the earthquake, it appears that the pressure axis (P-axis) of the focal mechanism has a 4-degree azimuth, which means that the pressure axis projection on a flat surface in the North direction only shifts 4 degrees towards the East. This data is in accordance with the movement direction of the Lombok area which was analyzed from the GPS data that moved towards N-NE. This shows that in the fault plane, there is a reaction force, as the force that holds the pressure from the Indo-Australian oceanic plate toward the North, slightly to the East which is indicated by the GPS monitored movement. As a consequence of the two forces on the fault plane that meet each other, an earthquake occurs as a manifestation of energy release. It is because the elasticity of the rocks has been exceeded that is unable to hold the force. 
Deformation caused or abandoned after the earthquake shows that it is approaching the fault plane. The value is getting bigger and decreasing when it moves away from the fault plane. This corresponds to the level of damage that is greater as the North approaches the epicenter.

Similarly that the results of satellite radar analysis obtained indicate that deformation is higher in the North than in the South. This shows that there is a weak zone in the North in the form of a fault plane where the earthquake occurs. These results are consistent with the fault type of analysis results of the focal mechanism showing a rising fault, which indicates that the Lombok block which is rising is pushed by other blocks on the Flores Back Trust. The imperfections in the material elasticity of Lombok cause higher deformation that occurs near the fault plane. The results of the radar analysis of the deformation that occurs clarify that the fault type where the earthquake occurs is a rising fault (thrust fault). The remaining deformation due to elastic rebound and elasticity of local rock is still well observed with the InSAR satellite radar image. This is consistent with the elastic rebound theory, and the elastic nature of the under stress material in which it does not return immediately even though the cause of the stress has released its energy.

From the three results of the analysis of GPS continuous observation before the occurrence, the analysis of earthquake signals that produce focal mechanisms as an embodiment of the fault mechanism during an earthquake and the results of satellite image analysis show that the results correspond to each other.

The results of the focal mechanism analysis as a manifestation of occurrence in Lombok show that the force system that works at the time of the earthquake has a direction leaning to the North (azimuth 4 degrees). The direction of this force corresponds to the relative direction of the Indo-Australian tectonic plate moving toward the Eurasian plate which means that the earthquake activity on Flores Back Thrust is closely related to the tectonic force system. So, Flores Back Thrust increasingly exists as a product of Indo-Australian pressure toward Eurasia, in the Nusa Tenggara region including Lombok. Flores Back Thrust is a weak area that is also a source of active earthquakes.

Associated with GPS observations of Lombok force and movement, Indo-Australian plate movements are very much consistent. So that it can be said that the results of the earthquake signal analysis to find out the fault movements of the focal mechanism is proven to be true according to the real conditions.

From the analysis of radar satellite image, it shows dominant deformation in the North with deformation rates decreasing further to the South which is in line with the level of local damage. This points out that the concentration of forces causing deformation and the earthquake in Lombok was concentrated in the North. The pattern of decline corresponds to the direction of the tectonic force observed by GPS. It can be said that between the results of the focal mechanism analysis, GPS observations and satellite image analysis with the DinSar method show the corresponding results, which means all three can be used as a method of knowing the deformation process that accompanies the earthquake process.

The focal mechanism analysis has the advantage of being able to be analyzed together with the analysis of earthquake parameters shortly after the earthquake. It can be seen the direction of the fault movement, the direction of the $\mathrm{P}$ axis (pressure), and the strength of the earthquake 
from the moment of the earthquake which is believed to be more representative in stating the strength of the earthquake. The results analysis of GPS observation can determine the direction of the pressure force from the direction of the very point from time to time so that it can be used as a correction of global motion of one tectonic plate relative motion with the other that coexist. While the results of radar satellite image analysis can provide information on the vertical deformation of the deformation distribution, as general information to the response rate of initial rock toward the deformation due to tectonic forces during an earthquake.

\section{Conclusion}

From the comparison of the results of the focal mechanism analysis, satellite radar, and movement of the earth's crust from GPS for Lombok earthquake on 5 and August 19, 2018, it can be concluded that there is a correspondence in the direction of the forces acting on Lombok Island due to tectonic forces around Lombok, both from the GPS data results and Focal Mechanism Data which are in the same direction of N-NE. The type of fault from the focal mechanism analysis, according to Flores Back Thrust, is a rising fault. The results analysis of the maximum deformation in the North indicate that the north side of Lombok as the side that is lifted up by the force system due to the pressure of other blocks on the Northside of the fault plane.

\section{Acknowledgments}

Thanks to Cyntia for helping to 'run' imh satellite radar data to obtain a deformation map of Lombok Island. We would also like to thank the Management of Sekolah Tinggi Meteorologi, Klimatologi dan Geofisika, especially UP3KM, that provided support in this research.

\section{References}

Bolt, B. (2006). Earthquakes. New York: WH Freeman and New York Comm.

Cronin, V. (2010). A Primer on Focal Mechanism Solution for Geologists. Texas: Baylor University.

Cyntia, C., \& Pudja, I. P. (2018). Subsidence analysis in DKI Jakarta using Differential Interferometry Synthetic Aperture Radar (DInSAR) Method. Sustinere: Journal of Environment and Sustainability, 2(3), 118-127.

Francis, P. W., Wadge, G., \& Mouginis-Mark, P. (1996). Satellite monitoring of volcanoes. In R. Scarpa \& R. . Tilling (Eds.), Monitoring and mitigation of volcano hazards. New York: Springer Verlag.

Ghose, R., \& Oike, K. (1988). Characteristics of Seismicity Distribution along the Sunda Arc: Some New Observations. Bull. Disas. Prey. Res. Inst., Kyoto Univ., 38(332), 29-48.

Iwashita, K., Taniguchi, H., Kimura, H., \& Kasuga, Y. (2003). Effect of uplift on earthquake response of building. Journal of Structural and Construction Engineering, 567, 33-40.

Marshall, J. (2005). 2004 Sumatra Earthquake \& Indian Ocean Tsunami. Pomona, California, USA.

Nugroho, H., Harris, R., Lestariya, A. W., \& Maruf, B. (2009). Plate boundary reorganization in the active Banda Arc-continent collision: Insights from new GPS measurements. Tectonophysics, 479(1-2), 52-65. 
Sasaki, T., \& Tamura, K. (2004). Prediction of liquefaction-induced uplift displacement of underground structures. In 36th Joint Meeting US-Japan Panel on Wind and Seismic Effects (pp. 191-198).

Sulaeman, C., \& Minarno, P. A. (2019). Deformasi PulauLombok Berdasarkan Data GPS. Jurnal Lingkungan Dan Bencana Geologi, 10(1), 11-18.

USGS. (2018). M 6.9 - 1km S of Belanting, Indonesia. The USA. 